\title{
Casemanagement bij beginnende dementie
}

\begin{abstract}
Samenvatting
Jansen APD, Van Hout HPJ, Nijpels G, Rijmen F, Dröes RM, Pot AM, Schellevis FG, Stalman WAB, Van Marwijk HWJ. Casemanagement bij beginnende dementie. Huisarts Wet 2011;55(2):58-63.

DoEL Men neemt algemeen aan dat vroegtijdige diagnose en casemanagement leiden tot betere zorg voor thuiswonende ouderen met dementie, vooral doordat de mantelzorger betere ondersteuning krijgt. Dat klinkt plausibel, maar het is niet bewezen. In een gerandomiseerd gecontroleerd klinisch onderzoek (RCT) gingen wij na of ouderen met de eerste symptomen van cognitieve achteruitgang en hun mantelzorgers daadwerkelijk beter af zijn met casemanagement dan met de gebruikelijke zorg die de huisarts biedt.
\end{abstract}

METHODE De deelnemers aan ons onderzoek waren 99 patiënten uit Westfriese huisartsenpraktijken, met hun belangrijkste mantelzorger. De patiënten waren 65 jaar of ouder, woonden thuis en hadden symptomen van cognitieve achteruitgang. Wij randomiseerden de koppels in een groep die casemanagement kreeg en een groep die de gebruikelijke huisartsenzorg ontving, en maten bij de mantelzorgers de ervaren competentie, zorgbelasting, kwaliteit van leven en mate van somberheid. De patiënten ondervroegen we over hun ervaren kwaliteit van leven. Dit deden we op drie meetmomenten: voorafgaand aan de randomisatie, na zes en na twaalf maanden.

RESULTATEN We vonden geen verschillen tussen de interventie- en de controlegroep.

CoNCLUSIE Wij hebben de meerwaarde van casemanagement vooralsnog niet kunnen aantonen, maar op basis van deze ene RCT is het nog te vroeg voor een definitief oordeel. Daarvoor is meer onderzoek nodig.

\section{INLEIDING}

$\mathbf{V}_{\mathrm{t}}^{\mathrm{o}}$ oor de huisartsgeneeskunde vormt het toenemend aantal thuiswonende ouderen met dementie een uitdaging, met name ook vanwege de gezondheidsrisico's voor de mantelzorgers, ${ }^{1}$ met een prominente plaats voor angst en depressie. ${ }^{2}$

De diagnose dementie wordt vaak pas laat in het ziekteproces gesteld. Zorgverleners nemen over het algemeen aan dat ouderen met dementie en hun mantelzorgers erbij gebaat zijn dat de diagnose - aan de hand van afwijkende resultaten op cognitieve tests - vroegtijdig gesteld wordt en de begeleiding

VUmc, EMCO+ instituut, afdeling Huisartsgeneeskunde, Van der Boechorststraat 7, 1081 BT Amsterdam: dr. A.P.D. Jansen; dr. H.P.J. van Hout; prof.dr. G. Nijpels; prof.dr. F.G. Schellevis; prof.dr. W.A.B. Stalman; dr. H.W.J. van Marwijk. VUmc, EMCO+ instituut: prof.dr. R.M. Dröes; dr. A.M. Pot. VUmc, afdeling Klinische epidemiologie en biostatistiek: dr. F.Rijmen • Correspondentie: d.jansen@vumc. $\mathrm{nl} \cdot$ Mogelijke belangenverstrengeling: dit project werd mogelijk gemaakt door een subsidie van ZonMw (2200.0114) en ISAO (03513). Het onderzoek is geregistreerd onder nummer ISCRTN83135728.

Een deel van dit artikel werd eerder gepubliceerd als: Jansen APD, Van Hout HPJ, Nijpels G, Rijmen F, Dröes RM, Pot AM, et al. Effectiveness of casemanagement among older adults with early symptoms of dementia and their primary informal caregivers: A randomized clinical trial. Int J Nurs Stud 2011;48:933-43. Publicatie gebeurt met toestemming van de uitgever. zo vroeg mogelijk in het ziekteproces begint. ${ }^{3}$ Deze veronderstelling is echter nooit getoetst in gerandomiseerd gecontroleerd klinisch onderzoek (RCT). Wel bevatten de richtlijnen van de organisatie Alzheimer Europe de aanbeveling om casemanagement aan te bieden aan thuiswonende ouderen bij wie de diagnose gesteld is, én aan hun mantelzorgers. ${ }^{4}$

Wij hebben deze RCT uitgevoerd om te bepalen of casemanagement in de huisartsenpraktijk daadwerkelijk effectiever is dan de gebruikelijke zorg voor thuiswonende oudere patiënten met symptomen van dementie en hun mantelzorgers. De medisch-ethische toetsingscommissie van het VUmc gaf toestemming voor dit onderzoek.

\section{METHODE}

\section{Onderzoeksopzet}

In deze RCT verdeelden wij koppels van patiënten en mantelzorgers via loting over twee groepen: casemanagement en gebruikelijke zorg. De patiënten behoorden tot de patiëntenpopulatie van 55 Westfriese huisartsen. Potentiële deelnemers ontvingen een informatiebrief en vulden een toestemmingsformulier in. Wanneer een patiënt (tijdelijk) niet in staat was tot een zelfstandige afweging, vroegen we verwanten om toestemming tot deelname.

\section{DOELGROEP}

De deelnemers moesten ouder zijn dan 65 jaar en daarnaast voldoen aan drie inclusiecriteria.

1. De huisarts vermoedde de eerste symptomen van cognitieve achteruitgang bij een patiënt, of de patiënt gaf dit aan op een door de huisarts opgestuurde screeninglijst, de

\section{Wat is bekend?}

- Mantelzorg verlenen aan ouderen met dementie kan slecht zijn voor de gezondheid van de mantelzorger en bijvoorbeeld leiden tot depressieve klachten.

- De diagnose dementie wordt vaak pas laat gesteld, terwijl de patiënt en de mantelzorger vaak al veel eerder behoefte hebben aan ondersteuning.

- Men neemt aan dat vroege herkenning en casemanagement de situatie van zowel de patiënt als de mantelzorger kunnen verbeteren. Er is echter geen bewijs voor deze aanname.

\section{Wat is nieuw?}

- Voor de mantelzorgers van thuiswonende ouderen levert casemanagement bij de eerste symptomen van cognitieve achteruitgang geen extra voordeel op in termen van ervaren competentie, ervaren zorgbelasting en mate van somberheid.

- Ook voor de kwaliteit van leven van de betreffende patiënten heeft casemanagement geen meerwaarde ten opzichte van de gebruikelijke zorg door de huisarts. 
Informant Questionnaire on Cognitive Decline (IQCODE). ${ }^{5}$

2. De patiënt scoorde lager dan 24 op de Mini Mental State Examination (MMSE) ${ }^{6}$, of had volgens de Seven Minute Screen (7MS) een risico van meer dan $50 \%$ op dementie. ${ }^{7}$ De patiënt had een mantelzorger.

Van deelname uitgesloten werden patiënten die (gespecialiseerde) ondersteuning ontvingen voor cognitieve problemen, terminaal ziek waren of de Nederlandse taal onvoldoende beheersten.

Van de patiënten die aan alle voorwaarden voldeden, benaderden we de belangrijkste mantelzorger, dat wil zeggen degene die het hele zorgproces coördineerde en/of meeste uren aan de zorg besteedde. Exclusiecriteria voor mantelzorgers waren het verstrekken van minder dan één uur mantelzorg per week en onvoldoende beheersing van de Nederlandse taal.

\section{Interventie: casemanagement}

Casemanagement is een gespecialiseerde vorm van zorg- en dienstverlening aan mensen die grote behoefte hebben aan zorg en ondersteuning of die het risico lopen onvoldoende zorg te ontvangen. Drie verpleegkundigen, werkzaam bij een thuiszorgorganisatie, verzorgden een jaar lang het casemanagement voor de interventiegroep. Zij startten het zorgtraject met een huisbezoek waarin ze onder andere de Resident Assessment Instrument Home Care (RAI-HC) afnamen, ${ }^{8}$ een vragenlijst die de diverse domeinen van het functioneren van de oudere in kaart brengt en dertig potentiële en actuele zorgproblemen signaleert. Aan de hand van de informatie die de RAI opleverde, stelde de verpleegkundige samen met de deelnemers een zorgplan op.

In het tweede huisbezoek maakten de casemanagers een plan van aanpak voor de situatie van de mantelzorger aan de hand van een draagkrachtlijst van het voormalige KwaliteitsInstituut voor Toegepaste ThuisZorgvernieuwing (KITTZ). ${ }^{9}$ De mantelzorgers ontvingen de mantelzorggids van het Steunpunt Mantelzorg met tips en een overzicht van alle beschikbare zorgprofessionals voor mantelzorgers.

Hierna coördineerden de casemanagers de zorg rondom het koppel, volgden ze de situatie en hielden ze de huisarts op de hoogte.

\section{Controle: gebruikelijke zorg}

De deelnemers in de controlegroep ontvingen een brief met het advies contact op te nemen met de huisarts. Zij regelden de benodigde zorg verder op eigen initiatief.

\section{Metingen en uitkomstmaten}

Er waren drie meetmomenten, eenmaal bij aanvang van het onderzoek (voorafgaand aan randomisatie), zes maanden nadien en twaalf maanden nadien. De mantelzorger vulde bij deze gelegenheden een viertal vragenlijsten in.

1. De Short Sense of Competence Questionnaire (SCQ) meet het gevoel van competentie in het verstrekken van mantelzorg op drie subschalen: consequenties voor het leven van

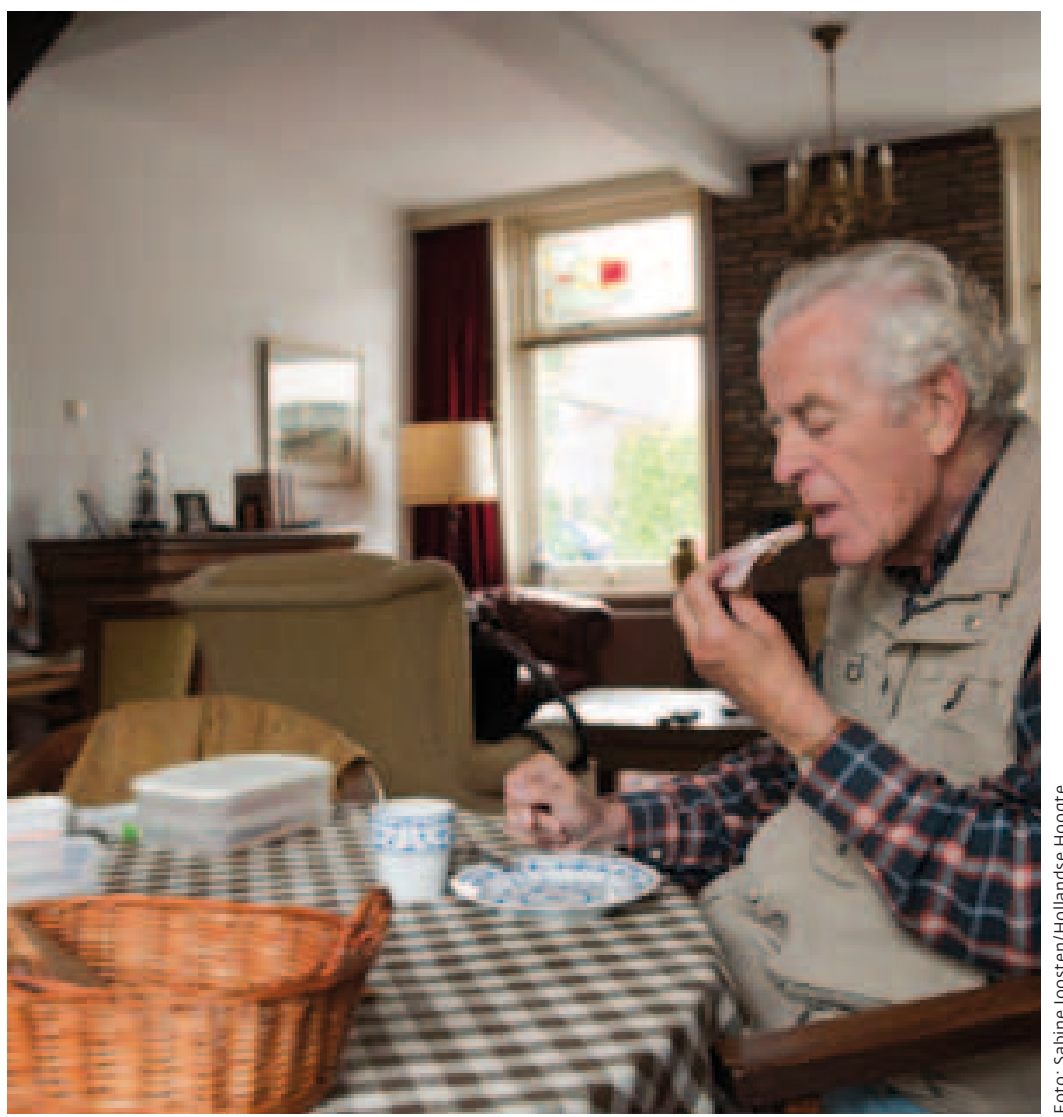

Figuur Stroomschema van het onderzoek

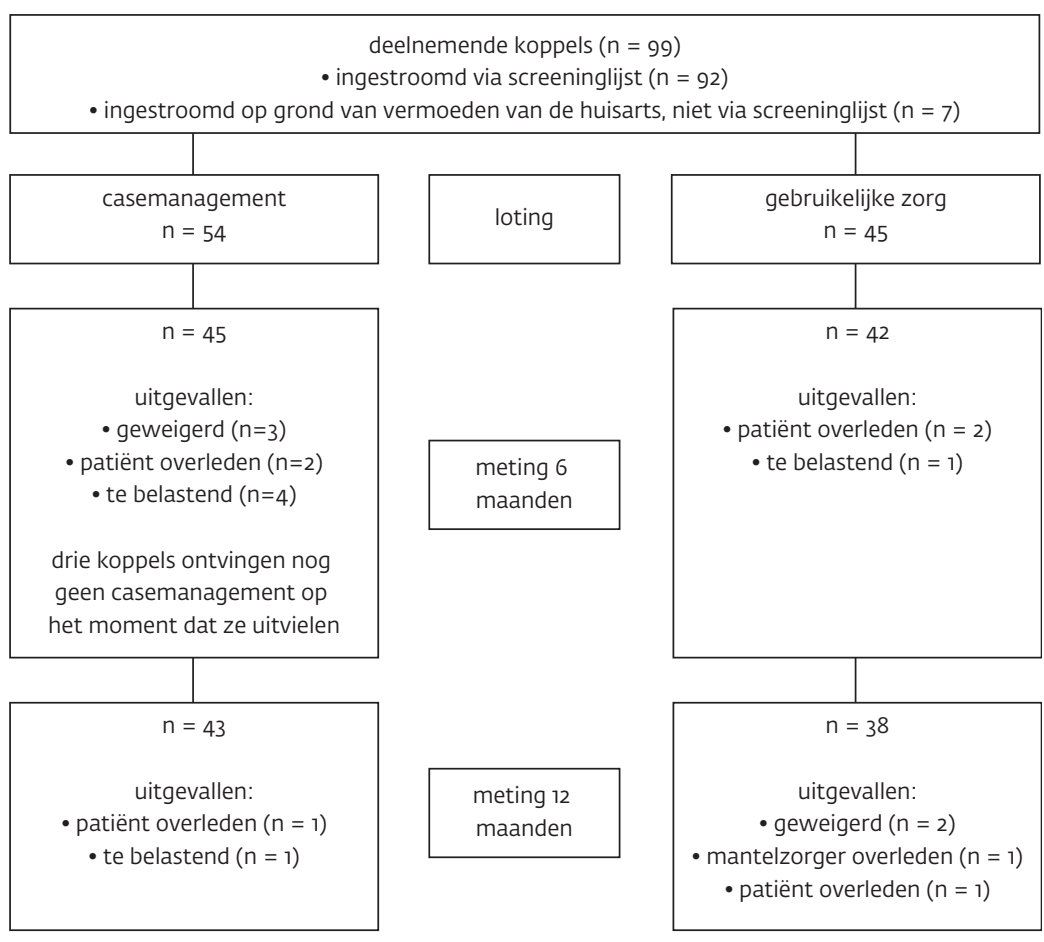


de mantelzorger, tevredenheid met het eigen functioneren als mantelzorger en tevredenheid met de zorgontvanger. ${ }^{10}$

2. De vragenlijst Ervaren Druk door Informele Zorg (EDIZ) meet de ervaren zorgbelasting. ${ }^{11}$

3. De MOS 36-item Short-Form health survey (SF-36) meet de kwaliteit van leven. ${ }^{12}$

4. De Center for Epidemiologic Studies Depression Scale (CESD) meet de mate van somberheid. ${ }^{13}$

Bij de patiënt maten wij de kwaliteit van leven driemaal in een interview op basis van het Dementia Quality of Life Instrument (DQoL). ${ }^{14}$ Naast het eigen oordeel over de kwaliteit van leven levert dit instrument een score op vijf subschalen: eigenwaarde, positieve emoties, negatieve emoties, het gevoel ergens thuis te horen en de mate waarin genoten wordt van zaken in de omgeving (zoals muziek en de natuur).

\section{Analyses}

Alle analyses vonden plaats volgens het intention-to-treatprincipe, dus ervan uitgaande dat alle koppels in beide onderzoeksgroepen de toegewezen interventie ook daadwerkelijk ontvangen hadden. Voor het vaststellen van eventuele verschillen in het beloop van de uitkomstmaten tussen de twee groepen gebruikten wij een linear mixed model met ongestructureerde covariantie. ${ }^{15}$

\section{RESULTATEN}

\section{Kenmerken van de deelnemers}

Tussen februari 2004 en juni 2005 startten 99 koppels met het onderzoek. Aan het einde van het onderzoek participeerden nog 81 koppels. De [figuur] bevat het stroomschema van het onderzoek.

De [tabellen 1, 2 en 3] tonen achtereenvolgens de sociale en demografische kenmerken van de deelnemers, het functioneren

Tabel 1 Sociale en demografische kenmerken van de deelnemers

\begin{tabular}{|c|c|c|c|c|}
\hline Kenmerk & $\begin{array}{l}\text { Case- } \\
\text { management }\end{array}$ & $\mathrm{n}$ & $\begin{array}{l}\text { Gebruikelijke } \\
\text { zorg }\end{array}$ & $\mathrm{n}$ \\
\hline \multicolumn{5}{|l|}{ Mantelzorger } \\
\hline Gemiddelde leeftijd, jaar (SD) & $63,6(13,8)$ & 51 & $61,6(15,2)$ & 41 \\
\hline Geslacht vrouw, frequentie & 36 & 54 & 33 & 45 \\
\hline $\begin{array}{l}\text { Relatie met de zorgontvanger, } \\
\text { aantal: }\end{array}$ & & 53 & & 44 \\
\hline - partner & 22 & & 18 & \\
\hline - kind & 26 & & 22 & \\
\hline - schoonkind & 1 & & 3 & \\
\hline - anders & 4 & & 1 & \\
\hline $\begin{array}{l}\text { Samenwonend met de } \\
\text { zorgontvanger, aantal }\end{array}$ & 27 & 54 & 19 & 44 \\
\hline $\begin{array}{l}\text { Aantal uren mantelzorg per week, } \\
\text { mediaan ( } 25 e-75 e \text { percentiel) }\end{array}$ & $7,0(3,4-67,5)$ & 38 & $10,0(3,0-20,0)$ & 31 \\
\hline \multicolumn{5}{|l|}{ Patiënt } \\
\hline Gemiddelde leeftijd, jaar (SD) & $82,1(5,7)$ & 54 & $81,0(6,5)$ & 45 \\
\hline Geslacht vrouw, aantal & 38 & 54 & 26 & 45 \\
\hline
\end{tabular}

en de scores op uitkomstmaten bij aanvang van het onderzoek. Significante verschillen tussen de twee onderzoeksgroepen waren er bij aanvang van het onderzoek alleen in de door de mantelzorger ervaren sociale steun $(t=2,483$; $\mathrm{p}=$ $\mathrm{o}, 015),{ }^{16}$ het aantal maanden dat de patiënt al cognitieve problemen had (mann-whitneytoets $U=353,00 ; p=0,003$ ) en de tevredenheid van de mantelzorger met de zorgontvanger $(\mathrm{t}=$ 2,o93; $\mathrm{p}=$ o,039).

De mantelzorgers rapporteerden relatief weinig negatieve consequenties van het geven van mantelzorg, weinig gedragsproblemen bij patiënten en weinig stress door gedragsproblemen. Gedurende het onderzoeksjaar werd bij 23 van de 99 deelnemende patiënten de diagnose dementie gesteld.

\section{Effecten van de interventie}

In onze vervolgmetingen bleek dat beide groepen zich op dezelfde wijze ontwikkelden. [Tabel 4] laat zien dat onze uitkomstmaten stabiel bleven, op drie na: de mate waarin patiënten genoten van zaken in de omgeving, de tevredenheid van de mantelzorger met de zorgontvanger en de consequenties van het geven van mantelzorg voor het leven van de mantelzorger. Deze drie uitkomstmaten gingen in beide groepen achteruit.

Tabel 2 Functioneren bij aanvang van het onderzoek

\begin{tabular}{|c|c|c|c|c|c|}
\hline Eigenschappen & $\begin{array}{l}\text { Test, } \\
\text { schaalbereik }\end{array}$ & $\begin{array}{l}\text { Case- }^{-} \\
\text {management }\end{array}$ & $\mathrm{n}$ & $\begin{array}{l}\text { Gebruike- } \\
\text { lijke zorg }\end{array}$ & $n$ \\
\hline \multicolumn{6}{|l|}{ Mantelzorger } \\
\hline $\begin{array}{l}\text { Zelf gerapporteerde } \\
\text { gezondheid, (erg) goed } \\
\text { of uitstekend }\end{array}$ & & 35 & 51 & 30 & 42 \\
\hline $\begin{array}{l}\text { Meer dan één } \\
\text { chronische ziekte }\end{array}$ & & 36 & 51 & 25 & 42 \\
\hline $\begin{array}{l}\text { Ervaren sociale steun, } \\
\text { gemiddeld (SD) }\end{array}$ & $\begin{array}{l}\text { SSL-i, } \\
34-136^{*}\end{array}$ & $65,5(12,0)$ & 50 & $\begin{array}{r}73,2 \\
(16,7)\end{array}$ & 41 \\
\hline $\begin{array}{l}\text { Stress van de } \\
\text { mantelzorger door } \\
\text { neuropsychiatrische } \\
\text { symptomen van de } \\
\text { zorgontvanger }^{\dagger} \text {, } \\
\text { gemiddeld (SD) }\end{array}$ & $\begin{array}{l}\mathrm{NPI}-\mathrm{Q} \\
\text { distress, } \\
0-60^{\#}\end{array}$ & $7,4(7,6)$ & 50 & $7,4(8,9)$ & 41 \\
\hline \multicolumn{6}{|l|}{ Patiënt } \\
\hline $\begin{array}{l}\text { Cognitief functioneren, } \\
\text { gemiddeld (SD) }\end{array}$ & MMSE, 0-30* & $22,0(4,2)$ & 53 & $\begin{array}{l}22,7 \\
(3,8)\end{array}$ & 43 \\
\hline $\begin{array}{l}\text { Cognitief functioneren, } \\
\text { mediaan (5e-10e } \\
\text { percentiel) }\end{array}$ & 7MS, 0-100" & $\begin{array}{r}100 \\
(64-83)\end{array}$ & 53 & $\begin{array}{r}100 \\
(0-64)\end{array}$ & 43 \\
\hline $\begin{array}{l}\text { Cognitief functioneren, } \\
\text { gemiddeld (SD) }\end{array}$ & $\begin{array}{l}\text { IQCODE, } \\
1-5^{\#, \neq}\end{array}$ & $4,1(0,6)$ & 49 & $4,1(0,6)$ & 42 \\
\hline $\begin{array}{l}\text { Aantal maanden met } \\
\text { cognitieve problemen, } \\
\text { mediaan ( } 25 \mathrm{e}-75 \mathrm{e} \\
\text { percentiel) }\end{array}$ & $\ddagger$ & $\begin{array}{r}24,0(16,3 \\
36,0)\end{array}$ & 40 & $\begin{array}{r}36,0 \\
(24,0 \\
60,0)\end{array}$ & 30 \\
\hline $\begin{array}{l}\text { Ernst van neuropsychia- } \\
\text { trische symptomen, } \\
\text { gemiddeld (SD) }\end{array}$ & $\begin{array}{l}\text { NPI-Q } \\
\text { severity, } \\
0-36^{\#}\end{array}$ & $6,2(5,0)$ & 50 & $6,2(6,2)$ & 41 \\
\hline
\end{tabular}

Voor noten en legenda zie [tabel 3]. 


\section{BESCHOUWING}

Wij hebben in deze RCT niet kunnen aantonen dat ouderen met de eerste symptomen van cognitieve achteruitgang, en hun mantelzorgers, meer baat hebben bij casemanagement dan bij de gebruikelijke zorg van de huisarts.

\section{Sterke en zwakke punten}

Onze RCT voldeed aan veel kwaliteitseisen. Bij aanvang van het onderzoek verschilden de kenmerken van de interventieen de controlegroep nauwelijks, er was voldoende contrast tussen gebruikelijke zorg en casemanagement, het aantal uitvallers was laag voor een kwetsbare groep (18\%) en het is onwaarschijnlijk dat deelnemers in de controlegroep (elementen van) casemanagement ontvingen.

De (organisatie van) de zorg en de kenmerken van de deelnemende huisartsen waren representatief voor de regio (WestFriesland).

Ons onderzoek had ook enige beperkingen die het vinden van een effect wellicht in de weg stonden. Een beperking was de relatief kleine omvang van de deelnemersgroep. Dit vergroot de kans dat heel kleine verschillen in het beloop van de uitkomstmaten gemist werden. Een tweede bepreking is dat de duur en intensiteit van het casemanagement wellicht onvoldoende waren om de uitkomstmaten te beïnvloeden. De patiënten in ons onderzoek hadden nog relatief weinig problemen. Het kan zijn dat casemanagement voor deze doelgroep nog niet relevant genoeg is en daardoor niet volledig werd geïmplementeerd.

\section{Vergelijking met eerdere onderzoeken}

Voor zover wij weten is dit de eerste RCT die naging of casemanagement effectief is bij thuiswonende ouderen met de eerste symptomen van cognitieve achteruitgang en bij hun belangrijkste mantelzorgers. Er is wel vergelijkbaar onderzoek gedaan onder reed sediagnosticeerde patiënten. Hoewel we de effectiefste elementen toepasten uit de voor deze groep ontwikkelde zorgprogramma's ${ }^{17-19}$ vonden we geen voordelen.

\section{CONCLUSIE}

Wij vonden in onze deelnemersgroep geen meerwaarde van casemanagement. Een reden kan zijn dat casemanagement geen voordelen biedt als het in een vroeg stadium wordt aangeboden. De bevindingen van onze trial moeten echter met de nodige voorzichtigheid geïnterpreteerd worden, om drie redenen. Ten eerste is het mogelijk dat casemanagement voor deze groep wel effectief zou zijn als het beter geïmplementeerd wordt dan in onze interventiegroep. Ten tweede kan het zijn dat casemanagement (preventieve) voordelen biedt maar

Tabel 3 Score op uitkomstmaten bij aanvang van het onderzoek

\begin{tabular}{lllll} 
Eigenschappen & $\begin{array}{l}\text { Test, } \\
\text { schaalbereik }\end{array}$ & $\begin{array}{l}\text { Case- } \\
\text { management }\end{array}$ & $\begin{array}{l}\text { Gebruikelijke } \\
\text { zorg }\end{array}$ \\
\hline
\end{tabular}

Mantelzorger

(1) Gevoel van competentie in het verstrekken van mantelzorg, gemiddeld (SD)

(b) tevredenheid met het eigen functioneren als mantelzorger

SCQ, $8-40$

SCO $12-60 *$

$\mathrm{SCQ}, 7-35^{*}$

(c) tevredenheid met de zorgontvanger

EDIZ, 0-9\#

SF-36, 0-100\%,

(3) Kwaliteit van leven, gemiddeld (SD)

$51,0(9,1) \quad 51 \quad 47,6(9,9) \quad 42$

(a) mentale somscor

$44,6(10,1) \quad 51 \quad 48,0(11,6) \quad 42$

(b) fysieke somscore

CES-D, 0-60

Patiën

(5) Kwaliteit van leven, gemiddeld (SD)

DQOL, 1-5*

(a) eigenwaarde

(b) positieve emoties

(c) negatieve emoties

(d) het gevoel ergens thuis te horen

(e) de mate waarin genoten wordt van zaken in de omgeving,

zoals muziek en natuur

(f) oordeel over kwaliteit van leven

$10,6(5,9) \quad 50 \quad 11,5(7,8) \quad 42$

7MS = Seven Minute Screen. CES-D = Center for Epidemiologic Studies Depression Scale. DQoL = Dementia Quality of Life instrument. EDIZ = Ervaren Druk door Informele Zorg. GARS = Groningen Activity Restriction Scale. IDDD = Interview for Deterioration in Daily living activities in Dementia (ingevuld door de mantelzorger). IQCODE= Informant Questionnaire on Cognitive Decline in the elderly (ingevuld door de mantelzorger). MMSE = Mini Mental State Examination. $\mathrm{NPI}-\mathrm{Q}=$ Neuropsychiatric Inventory-Questionnaire. SD = standaarddeviatie. SF-36 = MOS 36-item Short-Form health survey. SCQ = Sense of Competence Questionnaire. SSL-i = Social Support List-interactions, subschaal Positieve interacties

De in een afwijkende kleur gedrukte resultaten zijn statistich significant $(p<0,05)$.

* Hogere scores staan voor een betere situatie.

\# Lagere scores staan voor een betere situatie.

† Z-scores, gemiddelde 50 en SD 10, scores lager dan 50 wijzen op slechtere kwaliteit van leven vergeleken met de Nederlandse referentiepopulatie.

‡ Ingevuld door mantelzorger. 
(1) Gevoel van competentie in het verstrekken van mantelzorg

(a) consequenties voor het leven van de mantelzorger (SCQ, 8-40*)

- baseline

- 6 maanden

- 12 maanden

(b) tevredenheid met het eigen functioneren als mantelzorger (SCQ, 12-60*)

- baseline

- 6 maanden

- 12 maanden

(c) tevredenheid met de zorgontvanger (SCQ, 7-35*)

- baseline

- 6 maanden

- 12 maanden

(2) Ervaren zorgbelasting (EDIZ, 0-9\#)

- baseline

- 6 maanden

- 12 maanden

(3) Kwaliteit van leven (SF-36, 0-100*)

(a) mentale somscore

- baseline

- 6 maanden

- 12 maanden

$$
\text { a }
$$

(b) fysieke somscore

- baseline

- 6 maanden

- 12 maanden

(4) Mate van somberheid (CES-D, 0-60\#)

- baseline

- 6 maanden

- 12 maanden

)

28

\begin{tabular}{|c|c|c|}
\hline & & achteruitgang in beide groepen \\
\hline 28,1 & 28,8 & $\mathrm{~T}: \mathrm{F}=4,74 ; \mathrm{p}=0,013$ \\
\hline 28,0 & 29,6 & $G: F=0,68 ; p=0,460$ \\
\hline \multirow[t]{2}{*}{27,1} & 27,7 & $T * G: F=0,55 ; p=0,494$ \\
\hline & & stabiel in beide groepen \\
\hline 48,6 & 49,7 & $\mathrm{~T}: \mathrm{F}=1,01 ; \mathrm{p}=0,140$ \\
\hline 46,6 & 49,9 & $G: F=2,16 ; p=0,120$ \\
\hline \multirow[t]{2}{*}{47,4} & 48,4 & $T * \mathrm{G}: F=2,48 ; p=0,105$ \\
\hline & & achteruitgang in beide groepen \\
\hline 29,0 & 30,8 & $\mathrm{~T}: \mathrm{F}=7,72 ; \mathrm{p}=0,001$ \\
\hline 28,4 & 29,6 & $G: F=3,12 ; p=0,081$ \\
\hline \multirow[t]{2}{*}{27,7} & 29,0 & $T * G: F=0,44 ; p=0,647$ \\
\hline & & stabiel in beide groepen \\
\hline 3,9 & 3,3 & $\mathrm{~T}: \mathrm{F}=3,05 ; \mathrm{p}=0,053$ \\
\hline 3,8 & 2,7 & $G: F=2,89 ; p=0,092$ \\
\hline 4,2 & 3,3 & $T * G: F=0,72 ; p=0,492$ \\
\hline
\end{tabular}

Patiënt

(5) Kwaliteit van leven (DQoL, 1-5*)

(a) eigenwaarde

- baseline

- 6 maanden

- 12 maanden

ties

(b) positieve emoties

- baseline

- 6 maanden

- 12 maanden

(c) negatieve emoties

- baseline

- 6 maanden

- 12 maanden

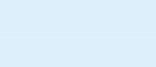

(d) het gevoel ergens thuis te horen

- baseline

- 6 maanden

- 12 maanden

(e) de mate waarin genoten wordt van zaken in de omgeving

- baseline

- 6 maanden

- 12 maanden

(f) oordeel over kwaliteit van leven

- baseline

- 6 maanden

- 12 maanden

$\begin{array}{rr}51,0 & 48,0 \\ 48,7 & 49, \\ 48,2 & 47,7 \\ 44,5 & 48,0 \\ 45,5 & 46, \\ 46,0 & 47,5 \\ 10,6 & 11, \\ 11,9 & 9,7 \\ 11,2 & 11,\end{array}$

stabiel in beide groepen

$\mathrm{T}: \mathrm{F}=1,38 ; \mathrm{p}=0,257$

$G: F=0,33 ; p=0,568$

$T * \mathrm{~F}: F=1,37 ; p=0,260$

stabiel in beide groepen

$\mathrm{T}: \mathrm{F}=0,41 ; \mathrm{p}=0,667$

$G: F=1,11 ; p=0,294$

$T^{* *} \mathrm{G}: F=1,06 ; p=0,353$

stabiel in beide groepen

$\mathrm{T}: \mathrm{F}=0,14 ; \mathrm{p}=0,867$

$G: F=0,18 ; p=0,669$

$T^{*} \mathrm{G}: \mathrm{F}=1,80 ; \mathrm{p}=0,172$

De maximale omvang was $n=54$ voor de groep met casemanagement en $n=45$ voor de groep met gebruikelijke zorg. Het linear mixed model levert schattingen voor de effecten van tijd $(T)$, groep $(G)$ en interactie tussen tijd en groep $\left(T^{*} \mathrm{G}\right)$ op de toetsgrootheid (F). Als alleen het tijdeffect T statistisch significant is, dan verandert de uitkomstmaat wel, maar voor beide groepen in gelijke mate (zie de rijen la, lc en 5 e). Is alleen het groepseffect $\mathrm{G}$ statistisch significant, dan duidt dat op een verschil tussen beide groepen dat gedurende de duur van de interventie niet verandert. Alleen een statistisch significante interactie T*G zou betekenen dat de uitkomstmaat per groep een verschillend beloop had, en dus dat het effect optrad waarin wij geïnteresseerd zijn. De tabel bevat echter geen statistisch significante $\mathrm{G}$ en $\mathrm{T}^{*} \mathrm{G}$. Voor de overige legenda zie [tabel 3]. 
dat deze nog niet zichtbaar zijn geworden tijdens het onderzoeksjaar. En ten derde heeft casemanagement wellicht toch (kleine) voordelen die wij als gevolg van de kleine steekproefomvang over het hoofd hebben gezien. Meer onderzoek zal hierover uitsluitsel moeten geven.

\section{LITERATUUR}

1 Torti FM, Gwyther LP, Reed SD, Freidman JY, Schulman KA. A multinat ional review of recent trends and reports in dementia caregiver burden. Alzheimer Dis Assoc Discord 2004;18:99-109.

2 Beach SR, Schulz R, Yee JL, Jackson S. Negative and positive health effects of caring for a disabled spouse: Longitudinal findings from the caregiver health effects study. Psychol Aging 2000;15:259-71.

3 Vernooij-Dassen MJ, Moniz-Cook ED, Woods RT, De Lepeleire J, Leuschner A, Zanetti O, et al. Factors affecting timely recognition and diagnosis of dementia across Europe: From awareness to stigma. Int J Geriatr Psychiatry 2005;20:377-86.

4 Alzheimer Europe. Dementia in Europe yearbook 2008. Luxembourg: Alzheimer Europe, 2008.

5 Jorm AF, Jacomb PA. The Informant Questionnaire on Cognitive Decline in the Elderly (IQCODE): Socio-demographic correlates, reliability, validity and some norms. Psychol Med 1989;19:1015-22.

6 Folstein M, Folstein S, McHugh P. 'Mini-Mental' State: A practical method for grading the cognitive state of patients for the clinician. J Psychiatr Res 1975;12:189-98.

7 Solomon PR, Hirschoff A, Kelly B, Relin M, Brush M, DeVeaux RD, et al. A 7 minute neurocognitive screening battery highly sensitive to Alzheimer's disease. Arch Neurol 1998;55:349-55.

8 Landi F, Tua E, Onder G, Carrara B, Sgadari A, Rinaldi C, et al. Minimum data set for home care: A valid instrument to assess frail older people living in the community. Med Care 2000;38:1184-90.
9 KITTZ. Draagkracht en draaglast vragenlijst voor mantelzorgers. Gronin gen: Van Gorcum, 1997.

10 Vernooij-Dassen MJ, Felling AJ, Brummelkamp E, Dauzenberg MG, Van den Bos GA, Grol R. Assessment of caregiver's competence in dealing with the burden of caregiving for a dementia patient: A Short Sense of Competence Questionnaire (SCQ) suitable for clinical practice. J Am Geriatr Soc 1999;47:256-7.

11 Pot AM, Van Dyck R, Deeg DJ. Ervaren druk door informele zorg: Constructie van een schaal. Tijdschr Gerontol Geriatr 1995;26:214-9.

12 McHorney CA, Ware JE Jr, Raczek AE. The MOS 36-Item Short-Form Health Survey (SF-36): II Psychometric and clinical tests of validity in measuring physical and mental health constructs. Med Care 1993;31:247-63.

13 Radloff LS. The CES-D Scale: A Self-Report Depression Scale for Research in the General Population. Applied Psychological Measurement 1977;1:385401.

14 Brod M, Steward AL, Sands L, Walton P. Conceptualization and measurement of quality of life in dementia: The dementia quality of life instrument (DQoL). Gerontologist 1999;39:25-35.

15 Fitzmaurice GM, Laird NM, Ware JH. Applied longitudinal analysis. Hoboken (NJ): Wiley, 2004.

16 Van Sonderen E. Het meten van sociale steun met de Sociale Steun LijstInteracties (SSL-i) en Sociale Steun Lijst Discrepanties (SSL-d): Een handleiding. Groningen: Noordelijk Centrum voor Gezondheidsvraagstukken (NCG), 1993.

17 Acton GJ, Kang J. Interventions to reduce the burden of caregiving for an adult with dementia: A meta-analysis. Res Nurs Health 2001;24:349-60.

18 Brodaty H, Green A, Koschera A. Meta-analysis of psychosocial interventions for caregivers of people with dementia. J Am Geriatr Soc 2003;51:65764.

19 Pusey H, Richards D. A systematic review of the effectiveness of psychosocial interventions for carers of people with dementia. Aging Ment Health 2001;5:107-19.

\section{Nico van Duijn}

\section{Pijn krijgt straf}

Bewegingsangst is niet meer durven bewegen uit angst voor pijn. Dat is een goede reflex als je enkel gebroken is. Als het gips eraf is, is het een verkeerde reflex. Dan moet je een beetje door de pijn heen lopen. Niet te veel, niet te weinig. Niet te vroeg, niet te laat. Dat is nu zo lastig, de vage grens tussen vermijden van die bewegingen en het opzoeken van de pijn door te bewegen.

Met schouderblessures is het net zo. Ooit viel ik van de trap, zijdelings, met mijn arm omhoog. Het voelde alsof mijn hele arm eraf scheurde. De fysiotherapeut en Moeder Natuur kregen die schouder in een paar weken redelijk op orde. Maar niet helemaal. Ik geef toe, ik mis de zelfdiscipline om die stomme oefeningen te doen.

Opeens kreeg ik door wat ik aan het doen was. Ik vermeed die arm te gebruiken. Kopjes opbergen hoog in de kast bijvoorbeeld, of mijn jas ophangen. Dat deed ik met mijn goede arm. Daar wist ik wat op. Die geblesseerde schouder moest voortaan alles doen. De gezonde arm kreeg vakantie, in een mitella. Pijnlijk of niet, aan het werk jij, mopperde ik op die nare schouder. Voortaan pakjij de vleespan van de bovenste plank, zonder hulp van de gezonde arm. En het bovenlicht open je zonder dat ik op een stoel ga staan. In de auto schakelen en sturen tegelijk. De zere arm deed braaf al het werk. Dat hielp. Binnen een maand kon ik alles weer, de pijn aan de arm was verdwenen. Bewegingen vermijden: het moet niet te lang duren. Geef de pijnlijke arm strafcorvee. 